\title{
Perú 2009: Los Legados Del AUTORITARISMO
}

\author{
Perú 2009: The Legacies of the Authoritarianism
}

\section{CARLOS MELÉNDEZ*}

Universidad de Notre Dame

\section{CARLOS LEÓN}

Pontificia Universidad Católica del Perú

\section{RESUMEN}

A casi una década de la apertura del régimen político posterior al gobierno de Alberto Fujimori (1990-2000), se hace evidente la fortaleza de los legados autoritarios que no han sido desmontados en su totalidad por los últimos dos gobiernos elegidos democráticamente. Los problemas de gobernabilidad que enfrenta el Perú, que se expresan a través de conflictos sociales (El Baguazo) y casos de corrupción estatal de alto nivel (Petroaudios), se originan precisamente en la herencia autoritaria del régimen anterior. Sin embargo, el actual gobierno ha logrado entrar en una lógica de convivencia con dichos legados autoritarios, aprovechando la ausencia de una oposición cohesionada y la fragmentación de las demandas sociales movilizadas.

Palabras clave: Perú, democracia, autoritarismo, gobernabilidad, conflictos sociales.

\begin{abstract}
Almost a decade from the opening of the political regime after Alberto Fujimori's administration (1990-2000), the strength of the authoritarian legacies, which have not been completely dismounted by the last two democratic governments, is evident. The challenges to governability that Peru faces are expressed by social conflicts (El Baguazo) and by high-profile officials' corruption scandals (Petroaudios), originated in the authoritarian legacies of the former political regime. However, the current administration has managed to create a logic of political coexistence with those authoritarian legacies, considering the opposition's lack of cohesion and the fragmentation of the mobilized social demands.
\end{abstract}

Key words: Peru, democracy, authoritarianism, governability, social conflicts. 
"En el Perú, el presidente tiene un poder. No puede hacer presidente al que él quisiera, pero sí puede evitar que sea presidente quien él no quiere. Yo lo he demostrado".

(Alan García, 24 de marzo del 2009).

Luego de casi una década de autoritarismo (1992-2000) (Cotler y Grompone, 2000), el Perú entró en una transición ordenada hacia un régimen político más competitivo (Tanaka y Vera, 2010). De este modo, en el 2001 se iniciaba un período de reconstrucción de la institucionalidad democrática con viejos partidos y nuevos actores que propugnaban asimilar las lecciones aprendidas de la "década de la antipolítica" (Degregori, 2000). Se llevaron a cabo reformas constitucionales, se legislaron nuevos marcos legales (Ley de Partidos Políticos, Ley de Gobiernos Regionales) y hasta reformas participativas para enraizar la democracia en todos los niveles, desde el local hasta el regional. Luego de ocho años del inicio de la apertura democrática, sin embargo, el legado del autoritarismo se hace latente.

Si bien es cierto que se han dado avances muy importantes (la sentencia judicial al ex Presidente Alberto Fujimori por 25 años ha sido ejemplar), la combinación de una democracia sin partidos y la permanencia de la herencia autoritaria complica las perspectivas de democratización del régimen y dificulta aún más el "juego de la gobernabilidad" que trata de llevar adelante el actual gobierno (Meléndez y León, 2009). Durante el 2009, la revelación de actos de corrupción a nivel de altos operadores del oficialismo (caso "Petroaudios") y el alto nivel de conflictividad social con significativas violaciones a los derechos humanos ("El Baguazo") socavan profundamente la legitimidad del gobierno. La baja aprobación presidencial y parlamentaria y los altos niveles de descontento popular (sobre todo en el interior del país) son la evidencia de la ruptura creciente entre la representación política y las demandas sociales, lo cual afecta la confianza en el gobierno y en los actores políticos. Ante este escenario, la ausencia de una oposición organizada y sólida impide que el descontento se capitalice hacia opciones alternativas. La gobernabilidad se convierte en un juego por default en el que el oficialismo se aferra a las cifras macroeconómicas que reiteran la imagen de un "país que avanza", pero cuya aparente eficiencia se ve desprestigiada por las redes de corrupción y el abuso a los derechos de los ciudadanos que ese modelo político de crecimiento parece implicar.

El artículo está dividido en tres partes. En la primera detallamos los elementos del optimismo oficialista: crecimiento económico, tratados internacionales en materia comercial, iniciativa nacionalista en política internacional (específicamente en el caso de la frontera con Chile) y procesamiento judicial de los actores del régimen autoritario fujimorista. Sin embargo, asimismo, detallamos los límites de este entusiasmo en un análisis de la evolución de los índices de aprobación de la actual administración. En la segunda parte, y a partir del análisis de los dos mayores escándalos políticos del segundo gobierno de García, desarrollamos la parte central de nuestro argumento: el asentamiento de la democracia y el alcance de un equilibrio de gobernabilidad entre actores institucionales e informales se ven obstaculizados por los legados autoritarios 
que se arrastran de la década anterior y que no han podido desmontarse. Bajo esta lógica analizamos las consecuencias de los legados autoritarios tanto en los principales actores institucionales (el Ejecutivo reacciona a las crisis políticas concentrando más poder en la figura presidencial y distanciándose del partido de gobierno; la oposición fragmentada no logra constituir el Legislativo como una arena para la lucha política y la construcción de alternativas) como en los actores informales (medios de comunicación dependientes del poder económico como la más significativa "oposición política" y una conflictividad social álgida pero fragmentada y desarticulada). En la tercera parte recapitulamos los argumentos principales y elaboramos las conclusiones.

\section{LA ARTIFICIALIDAD DEL OPTIMISMO OFICIALISTA}

\subsection{Crecimiento económico}

La economía peruana detuvo su tendencia de crecimiento ininterrumpido que se había iniciado en mayo del 2001, básicamente debido a las consecuencias de la recesión económica mundial que comenzaron a evidenciarse hacia fines del 2008. Sin embargo, el efecto de la crisis internacional no ha sido tan severo como en otros países. Si bien es cierto la tasa de crecimiento del PBI de 2009 fue de 0,9\% (Fuente: Banco Central de Reserva del Perú), un análisis mensual muestra una tendencia a la recuperación en el segundo semestre del año, en el que la economía peruana retomó su tendencia positiva. El PBI mensual volvió a crecer ligeramente a partir de agosto del 2009, cerrando el año con un $5 \%$ de crecimiento mensual ${ }^{1}$ (Gráfico 1). Con respecto a los indicadores de pobreza, estos mejoran paulatinamente. De acuerdo con las cifras del Instituto Nacional de Estadística e Informática, al iniciar el gobierno el $44,5 \%$ de la población se encontraba por debajo de la línea de pobreza. A inicios del 2009, este porcentaje era del $36 \%$. Asimismo, la pobreza extrema disminuyó del 16,1\% en el 2006 al 12,6\% a inicios del periodo de estudio. Estos avances, sin embargo, son relativizados por la permanencia de la desigualdad económica. El coeficiente de Gini no ha variado significativamente en lo que va del gobierno $(0,41$ en el 2006, 0,41 en el 2007, 0,39 en el 2008).

La evolución de la economía peruana se ve respaldada por promisorios tratados comerciales. Desde febrero del 2009 entró en vigencia el TLC entre Perú y Estados Unidos luego de la firma del acuerdo bilateral por el saliente presidente estadounidense George Bush y refrendado por Alan García bajo un decreto supremo. La consecución del acuerdo comercial, que fue un arduo camino iniciado en el 2004 bajo la administración de Alejandro Toledo, halló críticas por parte de la representación Demócrata que consideraba que la legislación laboral del Perú no se ajustaba aún a los compromisos requeridos. Por ello, se espera que con la administración Obama se hagan ajustes concernientes al uso

Un crecimiento tan cercano a $0 \%$ le dio la razón a economistas cuyos pronósticos fueron tildados de excesivamente pesimistas, como Waldo Mendoza, cuando los más críticos con la política económica de García pronosticaban un crecimiento de 3\%. Por su parte, el Ministerio de Economía y Finanzas (MEF) pronosticó que el Perú crecería 5\% durante la primera parte del año, pero con el paso de los meses ajustó varias veces sus propias proyecciones de crecimiento, sin llegar a poner proyecciones tan bajas como los obtenidos. Es decir, de crecer a tasas chinas $(9,8 \%)$, la crisis económica hizo que el Perú haya tenido la más fuerte "frenada" en crecimiento económico de la región con su $0,9 \%$. 
de mecanismo de resolución de disputas, los derechos laborales y legislación forestal. Evidentemente, la firma del convenio fue enmarcado por el gobierno dentro de su política de optimismo "El Perú Avanza", campaña publicitaria que utiliza la actual gestión para "comunicar" los logros del gobierno.

Gráfico 1: Crecimiento mensual del PBI durante el gobierno de Alan García (en porcentaje)

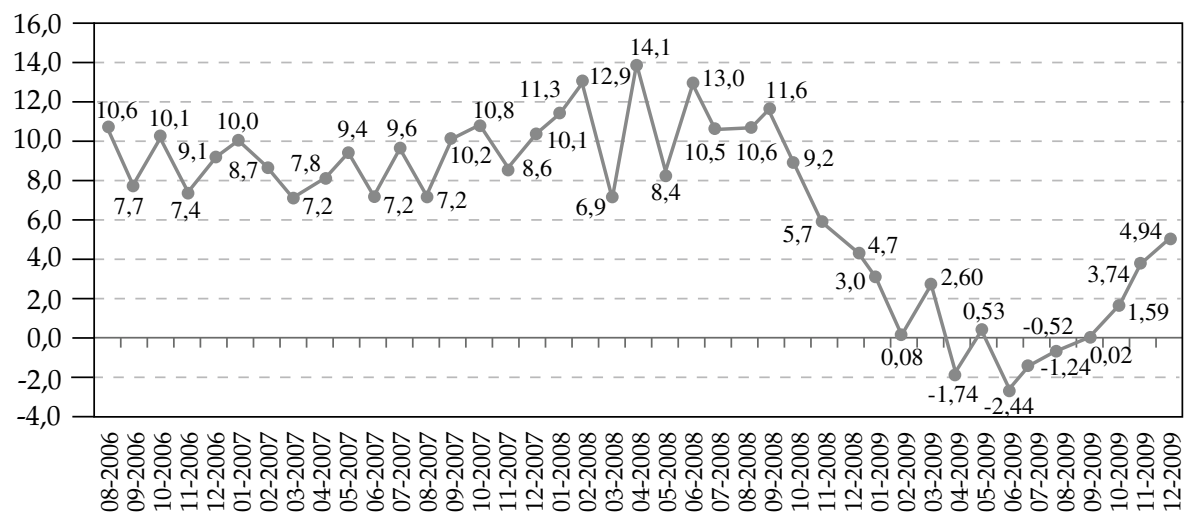

Fuente: Banco Central de Reserva del Perú.

\subsection{Las sentencias a Fujimori}

En abril del 2009, después de un largo proceso de 16 meses y 161 audiencias, la Sala Penal Especial de la Corte Suprema, presidida por el juez César San Martín, condenó a 25 años de prisión al ex presidente Alberto Fujimori al encontrarlo culpable de los cuatro casos que comprendían el juicio por violaciones de los derechos humanos (casos Barrios Altos, La Cantuta, secuestro del periodista Gustavo Gorriti, secuestro del empresario Samuel Dyer). De este modo, Fujimori se convierte en el primer ex presidente de la región elegido democráticamente en ser condenado por crímenes de lesa humanidad, sentando un importante precedente en la justicia internacional.

La resolución condenatoria es importante porque es contundente con el mayor responsable político del reciente período autoritario en el Perú (1992-2000). La misma refiere que Fujimori tuvo mando y comando máximo a nivel político y operativo, y lo señala "como autor mediato de la comisión de los delitos de homicidio calificado, asesinato bajo la circunstancia agravante de alevosía en agravio de las víctimas de los casos La Cantuta y Barrios Altos". El tribunal desestimó todos los argumentos de la defensa y estableció que Fujimori, de 70 años, permanecerá preso hasta el 10 de febrero de 2032, y además deberá indemnizar a 29 agraviados por un valor total de 90 mil dólares. Luego de la sentencia, Fujimori presentó una acción de nulidad que no ha prosperado. 
Más allá de lo emblemático que resulta la condena en materia de derechos humanos, al recibir Fujimori la pena más alta contemplada en el Código Penal, ésta grafica y sentencia el nivel de autoritarismo e impunidad que caracterizaron al régimen anterior. De acuerdo con la propia sentencia, Fujimori “estructuró y ejecutó una estrategia políticomilitar paralela a la que pregonaba públicamente, cuyo objetivo era la eliminación de terroristas, decisión que se articulaba por medio de su asesor Montesinos y del aparato organizado de poder que formó". La existencia de escuadrones paramilitares queda así develada como parte de una estructura jerárquica que tenía a Fujimori como el que "daba o avalaba" las órdenes criminales. Queda demostrado cómo un jefe de Estado, de un régimen elegido democráticamente en 1990, fue el culpable de estos crímenes contra los ciudadanos que debía proteger.

Asimismo, las siguientes sentencias fueron corroborando y haciendo justicia sobre otros aspectos del régimen autoritario que presidió Fujimori, pues también fue condenado a siete años por delitos de peculado o mal uso de fondos del Estado y falsedad ideológica, al hallarlo culpable por pagar US\$15 millones robados del tesoro público a su ex asesor de inteligencia Vladimiro Montesinos en setiembre del 2000. El balance que se hace luego de estas sentencias resulta en una mayor apreciación del régimen autoritario y corrupto que gobernó el país por diez años, sin contar aún con otros juicios pendientes.

Sin embargo, las sentencias contra Fujimori no han tenido un respaldo total de parte de la sociedad. No sólo algunos líderes de opinión se mostraron en contra de la magnitud de las penas, sino que de acuerdo con encuestas de opinión (Ipsos-Apoyo, abril y mayo 2009), un 27\% lo considera inocente de los crímenes de lesa humanidad (Caso Barrios Altos y La Cantuta) y un 17\% lo percibe como inocente de delitos de corrupción (Caso pago irregular de 15 millones a Montesinos). Cabe agregar que precisamente la hija del ex Presidente, Keiko Fujimori, lanzó su candidatura presidencial con miras a los comicios del 2011, y desde entonces goza de un respaldo sólido de alrededor del 20\%. A pesar de las sentencias, el fujimorismo se mantiene vigente y ha logrado convertirse en una fuerza política importante en el país.

\subsection{La demanda ante la Corte de La Haya}

Las disputas limítrofes entre Perú y Chile han sido constantemente un tema de impacto político. Durante 2009, dos hechos significativos se produjeron conforme las relaciones entre ambos países. En primer lugar, el 19 de marzo del 2009 el Perú entregó la memoria que sustenta la posición peruana en el contencioso de límites marítimos con Chile al secretario de la Corte Internacional de Justicia (CIJ) de La Haya que propugnan la tesis peruana de la defensa de las 200 millas y la inexistencia de un tratado de límites entre ambos países. Con ello se inicia el recurso procesal previsto en el estatuto y reglamento de la Corte que buscará poner fin a los reclamos peruanos por los límites marítimos frente a su vecino país del sur.

Evidentemente, el caso tuvo repercusión política. Alan García, en un breve discurso se refirió aquel día como uno de "unión nacional y de reivindicación" y se mostró confiado de lograr un fallo favorable al Perú. El proceso de demanda internacional -iniciado por 
el gobierno anterior- causó un apoyo unánime dentro de las diversas fuerzas políticas peruanas. Por otro lado, el gobierno de Michelle Bachelet se pronunció crítico de la demanda interpuesta. De hecho, el vicepresidente chileno Edmundo Pérez manifestó que la presentación de la memoria peruana "no ha sido un acto amistoso por parte de nuestros vecinos". Se supone que este proceso contencioso podría durar hasta el 2012.

Por otro lado, hacia fines de 2009, una segunda noticia causó una crisis diplomática con Chile. El suboficial de la Fuerza Aérea del Perú (FAP) Víctor Ariza Mendoza fue capturado y acusado de vender secretos militares a los servicios de inteligencia chilenos. Este descubrimiento -y la presunción de una red de espionaje más compleja en la FAPfue motivo para que el presidente García acusara a Chile de "atentar contra la soberanía del Perú", y calificó el espionaje como "un acto repulsivo que no corresponde a un país democrático". Por su parte, Bachelet calificó de ofensivas las palabras de García, pero no negó ni aceptó la denuncia peruana. Presumiblemente, se trataría de sectores de las fuerzas armadas chilenas que estuvieron detrás de este caso. La denuncia peruana coincidió con el anuncio de la propia Bachelet de una compra de armas valorada en US\$ 660 millones. El canciller peruano José García Belaúnde fue enfático al señalar que si Chile se cierra a la investigación "habrá que evaluar el conjunto de las relaciones". Por su parte, el canciller chileno Mariano Fernández dijo que de comprobarse que algún chileno está involucrado en el caso, será sancionado de acuerdo a la ley chilena.

\subsection{Aprobación presidencial}

A pesar de que podrían existir razones para corroborar la veracidad del eslogan de la campaña presidencial de 'El Perú Avanza', la opinión pública peruana muestra significativos niveles de desafección con respecto a la actual administración. El gobierno lo percibe como un problema comunicacional, ya que el crecimiento económico, la situación de la economía, la defensa de los intereses nacionales (con respecto a los referendos limítrofes con Chile) deberían interpretarse como buenas señales de la administración del país. Efectivamente, los primeros meses del 2009 la aprobación presidencial se incrementó con respecto al 2008. La resistencia de la economía a la crisis internacional y el TLC con Estados Unidos abonaron a favor del respaldo presidencial. Sin embargo, el segundo semestre el apoyo decreció significativamente, al punto de no recuperar el $30 \%$ de aprobación en lo que va del año.

Si promediamos las causas de la desaprobación a la actual gestión, de acuerdo con datos de Ipsos-Apoyo, dos de los principales motivos de la crítica a García se concentran en la economía. Durante el 2009, la principal causa de desaprobación es el incremento de los precios, seguido por la falta de trabajo, y en un tercer lugar por la deshonestidad del presidente ("no cumple con sus promesas"). La corrupción durante la actual gestión aparece como la cuarta causa de desaprobación. Sin embargo, lo que aparentemente determina la desafección con el gobierno es el ambiente de conflictividad social que merma la legitimidad no sólo del gobierno sino también del régimen. La abrupta caída del 30 al 21\% de aprobación en junio del 2009 coincide con uno de los errores más gruesos de la actual gestión: la represión policial a la manifestación de comunidades 
nativas en Bagua (Amazonas) que terminó con la vida de 25 ciudadanos (entre policías e indígenas). El desprestigio mermó la aprobación presidencial, pero rápidamente se compuso (aunque no a los niveles originales). La conflictividad social (ver acápite más adelante), aunque crea sensación de desgobierno y afecta coyunturalmente el prestigio de la administración, es todavía un elemento secundario dentro de la insatisfacción de las mayorías.

Gráfico 2: Aprobación presidencial y del Congreso, 2006-2009

(A nivel nacional)

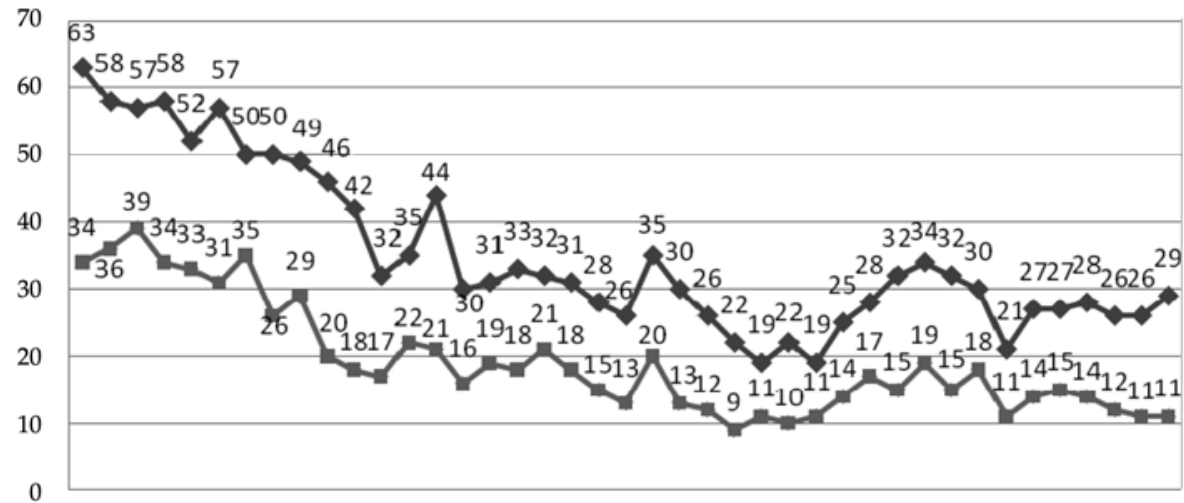

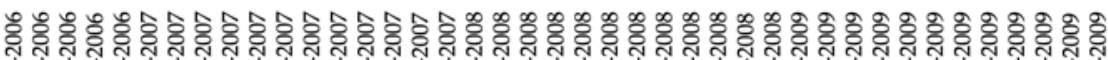

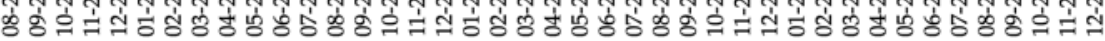

$\longrightarrow$ Aprobación presidencial $\quad \rightarrow$ Aprobación del Congreso

Fuente: Ipsos-Apoyo.

Un rasgo distintivo del 2009 con respecto a la aprobación presidencial y del Congreso, es que se hacen más evidentes las diferencias entre ambos poderes para la ciudadanía. Si bien hasta el 2008 la aprobación de ambas instituciones seguía tendencias similares, en el último año la evolución de ambos indicadores parecen tomar lógicas propias. Un análisis específico del 2009 permite evidenciar un declive permanente de la aprobación legislativa versus una leve mejoría de la presidencial (sobre todo en el segundo semestre).

El nivel de desafección ciudadana afecta al sistema político en su conjunto. Como lo señalamos en un artículo anterior (Meléndez y León, 2009), sólo el 43\% de los ciudadanos apoyan al sistema político (porcentaje que sólo supera a los resultados en Haití y Ecuador) (LAPOP, 2006). Si a ello sumamos la movilización social álgida de los últimos años, hay motivos para considerar que este divorcio entre sociedad y clase política es muy profundo. Sin embargo, y a pesar de la desconfianza creciente, el apoyo ciudadano al régimen democrático muestra una ligera recuperación (de $47 \%$ en el 2007, 45\% en el 
2008, a 52\% en el 2009), aunque todavía insuficiente como para eliminar los riesgos de una aventura autoritaria (ver Cuadro 1).

Cuadro 1: Apoyo a la democracia en el Perú, 1996-2009

\begin{tabular}{cccccccccc}
\hline Año & 2001 & 2002 & 2003 & 2004 & 2005 & 2006 & 2007 & 2008 & 2009 \\
\hline Porcentaje & 62 & 55 & 52 & 45 & 40 & 55 & 47 & 45 & 52 \\
\hline
\end{tabular}

Fuente: Latinobarómetro.

\subsection{Percepción de la corrupción}

El escándalo público de operadores políticos de alto rango para favorecer a determinadas concesiones de recursos energéticos (caso Petroaudios, ver siguiente acápite) gracias a audios procedentes de "services" privados de espionaje telefónico ha generado la sensación, al menos a partir de la cobertura periodística, de una administración estatal corroída por este tipo de prácticas que cuestionan la transparencia de cómo se operan los negocios en el país. Las denuncias involucran a altos cargos directivos del partido de gobierno y develan los arreglos "por debajo de la mesa" de la clase dirigencial.

Si bien es cierto este tipo de escándalos políticos perjudican la imagen del gobierno, vista en perspectiva comparada, el nivel de corrupción del régimen se encuentra en los niveles promedio latinoamericanos (ver Cuadro 2) de acuerdo con los datos proporcionados por el Banco Mundial. Luego de la aplicación del índice de Control de la Corrupción del Banco Mundial (que mide el grado en que el poder público se ejerce para obtener beneficios privados incluyendo la pequeña y la gran corrupción, así como la captura del Estado por parte de élites e intereses privados), los niveles de corrupción se encuentran alrededor de la media continental. Evidentemente, la existencia de estos niveles de corrupción afecta negativamente los niveles de gobernabilidad. De hecho, de acuerdo con el indicador de Gobernabilidad del Banco Mundial, el nivel de corrupción en el Perú afecta negativamente en un cuarto de punto el índice general de gobernabilidad; sin embargo, si se contempla la evolución de este indicador en los últimos años en el Perú, los niveles de corrupción han disminuido considerando cuán afectado estaba el sistema de toma de decisiones por negocios ilegales (narcotráfico y venta de armas, por ejemplo) que caracterizaron el régimen autoritario hasta el 2000.

Cuadro 2: Control de la corrupción en América Latina 2008

\begin{tabular}{lcc}
\hline \multicolumn{1}{c}{ País } & Percentil & $\begin{array}{c}(-2,5 \mathrm{a}+2,5) \\
\text { Puntaje de } \\
\text { Gobernabilidad }\end{array}$ \\
\hline Chile & 87,0 & $+1,31$ \\
Uruguay & 83,6 & $+1,12$ \\
Costa Rica & 70,0 & $+0,48$ \\
Brasil & 58,5 & $-0,03$ \\
\hline
\end{tabular}




\begin{tabular}{lcc}
\hline \multicolumn{1}{c}{ País } & Percentil & $\begin{array}{c}(-2,5 \mathrm{a}+2,5) \\
\text { Puntaje de } \\
\text { Gobernabilidad }\end{array}$ \\
\hline Panamá & 53,6 & $-0,15$ \\
El Salvador & 51,2 & $-0,22$ \\
Colombia & 50,2 & $-0,25$ \\
México & 49,8 & $-0,26$ \\
Perú & 49,3 & $-0,26$ \\
Argentina & 40,1 & $-0,44$ \\
Bolivia & 38,2 & $-0,47$ \\
Guatemala & 27,5 & $-0,72$ \\
Ecuador & 22,7 & $-0,79$ \\
Nicaragua & 21,3 & $-0,81$ \\
Honduras & 20,8 & $-0,82$ \\
Paraguay & 17,4 & $-0,93$ \\
Venezuela & 9,2 & $-1,13$ \\
\hline
\end{tabular}

Fuente: Banco Mundial.

\section{LOS LEGADOS DEL AUTORITARISMO EN LA DINÁMICA POLÍTICA}

El régimen autoritario fujimorista (1992-2000) se basó, entre otros, en dos principales elementos. En primer lugar, y a nivel de las elites de toma de decisiones, creó un aparato de espionaje en el Servicio de Inteligencia Nacional (SIN) a cargo de Vladimiro Montesinos que, a partir de la vigilancia ilícita a los opositores del régimen, fue creando una estructura de reglaje en base al "chuponeo telefónico" (interceptación telefónica) que se convirtió en el núcleo del quehacer político oficialista y a partir del cual se practicó el chantaje para perennizar los intereses del fujimorismo. El segundo elemento consistió en la estructuración de un aparato clientelar que tenía como referente el aparato estatal y los programas sociales. Dicha estructura fue apartidaria, y se basó en la satisfacción inmediata de prebendas puntuales a líderes locales que permitían controlar demandas sociales a partir del autoritarismo de un régimen con estados de excepción que interpretaba cualquier protesta ciudadana en una "amenaza terrorista". Al caer el régimen, el desmontaje tanto del aparato de espionaje y del aparato clientelar fueron mal resueltos. En el primer caso, los operadores de las maquinarias de espionaje se independizaron y se convirtieron en servicios privatizados "de seguridad", satisfaciendo así una demanda (tanto de parte de políticos como de empresarios) creada durante el fujimorismo. Las altas decisiones del país continúan siendo más fieles a los oídos de espías que a las demandas ciudadanas. En el segundo caso, la apertura democrática de un régimen sin partidos, vulneró cualquier posibilidad de intermediación política. Las demandas sociales obstaculizadas autoritariamente durante diez años rebalsaron una estructura de intermediación (partidos sin presencia social) debilitada por años de 
conflicto interno (1980-2000) y represión autoritaria (1992-2000). Sin reformas sustantivas en ambos aspectos, el actual país es un reflejo de soluciones truncas. Alberto Fujimori y Vladimiro Montesinos podrán estar presos, pero el país sigue enjaulado entre grabaciones ilícitas y conflictos que sólo se resuelven apelando a la mano dura. No es casual que las dos principales crisis políticas de la actual administración (que se desarrollaron en el 2009) se originan precisamente en estos legados autoritarios.

\subsection{El Perú post-SIN: Los Petroaudios}

Quimper: El ministro (de Energía y Minas, Juan Valdivia), feliz. ¿Viste el discurso que se mandó?

León: Sí pues.

Quimper: Lo mismo que (Daniel) Saba (Director de PeruPetro ${ }^{2}$ ). Y (César) Gutiérrez (director de PetroPerú ${ }^{3}$ ) prefirió sentarse a la mesa con ustedes que con... ¿cómo se llama?... que con el ministro.

León: ¿Por qué ah?

Quimper: Como una deferencia pues, a sus socios. (...) Entonces muy bien todo, hermano. Están contentos ellos ah. Es que hemos hecho un faenón, hermano. Ha incluido hasta servicio de inteligencia. Ahora, mejor que Petro-Tech ${ }^{4}$ haya agarrado dos lotes. Te voy a decir por qué. Porque los vamos a tener de vecinos.

(Conversación telefónica del 11 de setiembre del 2008; el día anterior el gobierno otorgó la buena pro a la empresa Discover Petroleum)

En octubre del 2008, diversas fuentes periodísticas hicieron públicos audios de conversaciones telefónicas entre operadores políticos allegados al gobierno y funcionarios públicos en los que se delatan irregularidades en las licitaciones de yacimientos petroleros. Con los audios, se evidencia una larga cadena de negociados detrás del "boom energético" que atraviesa el país, y aunque inicialmente no se involucra directamente a políticos de alto nivel, paulatinamente se va desatando la madeja que puede identificar responsabilidades

2 PeruPetro S.A. es la empresa estatal encargada de promover la inversión en actividades de exploración y explotación de hidrocarburos en el país. En representación del Estado, negocia, celebra y supervisa los contratos en materia hidrocarburífera, así como los Convenios de Evaluación Técnica. Asimismo, comercializa a través de terceros los hidrocarburos provenientes de las áreas bajo contrato, en la modalidad de servicios.

3 PetroPerú es una empresa estatal dedicada al transporte, refinación, distribución y comercialización de combustibles y otros productos derivados del petróleo. A diferencia de PeruPetro, la cual comercializa los lotes petroleros a nombre del Estado peruano, PetroPerú los explota como cualquier empresa.

4 Petro-Tech Peruana era una empresa dedicada a la exploración, desarrollo, producción y procesamiento de hidrocarburos en Perú. Fue una de las que concursó por la buena pro de los lotes petroleros junto con Discover Petroleum y una empresa colombiana, ganando Discover la mayoría de ellos. Inicialmente, se le acusó de estar detrás de los "petroaudios". Finalmente, en febrero del 2009, Ecopetrol (colombiana) y Knoc (Korea National Oil Corporation, compañía estatal de petróleo de Corea del Sur) adquirieron la compañía Offshore International Group Inc., cuyo principal activo era, precisamente, Petro-Tech Peruana S.A. 
que podrían llegar a las más altas esferas del poder. Pero al mismo tiempo, y quizás un hecho de mayor preocupación, es que se devela la existencia de empresas privadas de espionaje telefónico que, herederas del gran aparato de inteligencia que rentara Vladimiro Montesinos en la década de 1990, siguen vigentes e influyentes -aunque ahora privatizadas en services- entre políticos y empresarios de alto vuelo. Las decisiones importantes del país se toman así bajo un velo de filtraciones, espionaje y otras prácticas ilícitas.

A inicios del 2009 la Fiscalía identificó a quién había realizado la interceptación telefónica: la empresa "Business Track" (BTR), compuesta por miembros de la Marina del Perú (tres en retiro y dos en actividad) y con posesión de equipos de interceptación telefónica. En siguientes ocasiones les incautaron gran cantidad de archivos electrónicos producto de sus actividades ilícitas, entre USBs, discos duros y transcripciones. Con el transcurso de las investigaciones saldría a la luz que las dos cabezas de BTR, el Contralmirante (r) Elías Ponce Feijóo y el Capitán de Fragata (r) Carlos Tomasio di Lombardi, también habían trabajado en la interceptación de correos electrónicos durante los años finales del gobierno de Fujimori, cuando estaban en actividad. Esta estaba dirigida a políticos de la oposición y a periodistas críticos al gobierno, así como a activistas de derechos humanos.

Las conversaciones que salen a la luz y que involucran a los lobbyistas Rómulo León Alegría (ex ministro durante el primer gobierno aprista) y a Alberto Quimper permiten elaborar las primeras hipótesis sobre los negociados detrás. Estas apuntaban a que Petro-Tech Peruana (PTP), empresa que perdió una concesión importante ante Discover Petroleum, habría contratado los servicios de BTR o en todo caso serían quienes filtraron los audios. ${ }^{5}$

Business Track tuvo en un momento una relación cercana al Ejecutivo. En el año 2006, esta empresa, que se presentaba como dedicada a temas de seguridad, dio exposiciones a ministros sobre el riesgo que representaban las supuestas actividades de las FARC en el Perú, y llegó a advertir sobre un supuesto ataque a Palacio de Gobierno, amenazas que resultaron exageraciones artificialmente sobredimensionadas. Aunque Business Track se dedicaba inicialmente a dar consultorías sobre seguridad a empresas, también realizaba intercepciones telefónicas, electrónicas y seguimiento de personas ("reglaje") a quienes lo solicitaban. Contrario a lo que podría pensarse, BTR lo hizo de manera indiscriminada: sus blancos fueron tanto políticos de la oposición como a cercanos al gobierno, así como empresas.

En la actualidad, el caso de los "petroaudios" se lleva en dos procesos judiciales distintos. En uno se investiga todo lo referente a interceptación telefónica de Business Track y las personas y empresas que solicitaron sus servicios. En el otro se investiga todo lo referente a la irregular concesión de los lotes petroleros.

5 No se ha comprobado que Petro-Tech tenga que ver con el espionaje. Algunas evidencias apuntan a que fueron empresas ligadas al rubro del cemento las que tuvieron que ver con este tema. Al parecer, la trama inicial de espionaje no tenía como objetivo el petróleo, sino, más bien, una disputa comercial vinculada a la rebaja de aranceles del cemento, otorgada por el Ministerio de Economía y Finanzas luego del terremoto del 2007. 


\section{Las consecuencias políticas}

Una vez destapados los casos, la oposición y sobre todo los medios de comunicación independientes exigieron responsabilidad penal del entonces jefe del gabinete Jorge del Castillo y de los ministros de Energía Juan Valdivia y de Salud Garrido Lecca. ${ }^{6}$ Sin embargo, debido a la debilidad de la oposición en el Parlamento, el Congreso de la República no logró acusar penal ni constitucionalmente a los referidos ya que el pleno del Congreso aprobara la moción en mayoría de la comisión investigadora encargada del caso, en la que sólo se les encontraba como "responsables políticos".

Aún así, la secuela de los petroaudios seguiría trayendo problemas al Ejecutivo y cambios en el gabinete. La revista Caretas destapó a mediados de setiembre que la jueza María Elena Martínez, al revisar la documentación del caso Business Track, descubrió que el entonces Ministro de Vivienda Francis Allison tuvo un vínculo laboral con BTR desde setiembre de 2007 hasta setiembre de 2008; es decir, hasta apenas un mes antes del destape de los petroaudios. Según la documentación, Allison recibía un sueldo mensual por brindar asesoría legal a BTR. Según su versión, él daba servicios legales a varias empresas, y en el caso de BTR él era únicamente un asesor legal externo, sin conocimiento ni vinculación con sus actividades ilícitas; por ello, tampoco le informó a Alan García de ese vínculo laboral. Allison, citado por la Comisión del Congreso sobre interceptación telefónica, no pudo explicar satisfactoriamente la relación de dicho vínculo. Diez días después del destape, Allison renunció al Ministerio de Vivienda, denunciando "una campaña de demolición y de difamación" en su contra.

Por otra parte, en octubre César Gutiérrez, quien fue presidente de PetroPerú cuando esta empresa ganó junto a Discover Petroleum la concesión de los lotes petroleros, fue acusado por su ex esposa de haber recibido dinero por la concesión de los lotes petroleros a Discover Petroleum, y de ser pareja de Lily Lemasters, quien en el 2008 era traductora de Discover Petroleum y luego del escándalo de los petroaudios pasó a ser su representante.

La estrategia mediática del gobierno -mejor dicho, de García- en el caso Petroaudios durante el año 2009 ha sido desmarcarse de los actos de corrupción que puedan salir y pedir severidad para ellos, y poner un fuerte énfasis en la captura de las personas y empresas que pagaban el servicio de interceptación telefónica. Mientras, la oposición pide se investigue a fondo la posible red de corrupción destapada a raíz de los petroaudios, la cual según ellos involucraría a miembros del partido aprista y del Ejecutivo.

Es de tomar en cuenta que hasta el momento no ha salido a la luz ninguna interceptación de algún miembro del gobierno, aunque hay indicios que involucran a las grandes esferas. Por otro lado, cabe destacar que hasta ahora solo se encuentran con arresto los

6 Garrido Lecca fue involucrado en el caso debido a que fue referido en audios vinculados con la construcción de hospitales. También era el objetivo inicial del espionaje, debido a que las empresas peruanas de cemento lo sindicaban como el lobbyista de la rebaja de aranceles. 
responsables de la interceptación y quienes influyeron en la irregular concesión de los lotes petroleros (León y Quimper), no así quienes ordenaron la interceptación ni quienes se beneficiaron directamente con la concesión.

\subsection{El Baguazo y la conflictividad social en un país sin intermediación política}

"El Gobierno considera que esos decretos no son inconstitucionales. El partido aprista considera que ellos favorecen el desarrollo sostenible de los recursos naturales del país. Aquí hay politiquería radicaloide motivada por grupos violentistas".

(Mauricio Mulder, Secretario General del Partido Aprista y Congresista de la República. 5 de junio 2009).

Haciendo uso de las facultades legislativas que le delegó el Congreso en diciembre 2007 con el fin de adecuar la legislación nacional a los compromisos del TLC con EE.UU., el Ejecutivo emitió una serie de decretos legislativos para dicho fin en la primera mitad del 2008. Entre estos, se encontraban el decreto 1015, luego modificado por el decreto 1073, los cuales a decir de las organizaciones indígenas amazónicas agrupadas en AIDESEP atentaban contra sus tierras al facilitar su venta; incluso la misma Defensoría del Pueblo consideraba que los decretos eran inconstitucionales. Por ello, en agosto del 2008, AIDESEP realizó un paro amazónico pidiendo la derogación de los DL 1015 y 1073, el cual fue levantando cuando el pleno del Congreso derogó los decretos en cuestión tras 11 días de huelga y dos de tregua. Un agravante es que los decretos no fueron consultados con las comunidades, a pesar de que el Perú, como parte del convenio 169 de la OIT, está obligado a consultar las normas que involucren los derechos de las comunidades nativas.

Por entonces, uno de los acuerdos entre AIDESEP y la Presidencia del Congreso de Ministros a raíz de las protestas fue el de establecer una mesa de diálogo. Sin embargo, el día del establecimiento de la mesa AIDESEP se retira de ella debido a la presencia de la CONAP (Confederación de Nacionalidades Amazónicas del Perú), invitada por el Gobierno. AIDESEP considera que la CONAP no representa los intereses de los amazónicos, y la acusa de apoyar los intereses de las petroleras (CONAP firmó un contrato con PeruPetro).

AIDESEP mantenía su discrepancia sobre los decretos 1020, 1064, 1080, 1081, 1089 y 1090 -principalmente este último- promulgados conjuntamente con el DL 1015. En su Asamblea de Representantes a inicios del 2009 acordaron realizar protestas en defensa de sus territorios y "contrarios a su privatización", buscando con ello que el Congreso derogue los decretos mencionados. Mientras el gobierno decía que el fin de los decretos legislativos era proteger a la Amazonia de tala ilegal y de la minería informal, requisito de los legisladores demócratas para implementar el TLC con Estados Unidos, AIDESEP sostenía que en realidad el fin de los decretos era eliminar la inviolabilidad de las tierras 
comunitarias para así dejar el camino libre para privatizarlas a través de concesiones petroleras, así como para aprovechar los recursos hídricos de ellas.

Así, AIDESEP empezó sus protestas -otro "Paro Amazónico" - el 9 de abril, cerrando el tránsito fluvial en varios ríos y tomando estaciones petroleras. Las protestas iban desde Madre de Dios y Puno, en el suroriente, hasta Amazonas y Loreto hacia el nororiente, y Junín y Huánuco en la selva central. ${ }^{7}$ Poco a poco fue incluyendo paros en ciudades (como en Yurimaguas) y bloqueo de carreteras (como la llamada "Curva del Diablo" en Bagua). Nueve días después de iniciado el paro, el 20 de abril, los dirigentes de AIDESEP se reunieron con el presidente del Consejo de Ministros Yehude Simon, para buscar soluciones. De hecho, poco antes de la reunión, Alberto Pizango, líder de AIDESEP, dijo que parecía que el gobierno "estaba acostumbrado a que el pueblo endurezca sus medidas para que recién atienda los reclamos". No hubo acuerdo en esa reunión, y continuaron las tomas. Los awajún-wampis tomaron tres días después la Estación N ${ }^{\circ} 6$ del oleoducto Nor Peruano de PetroPerú en Bagua, coordinando con el jefe de operaciones de la estación la toma, y comprometiéndose a no dañar la instalación a cambio de paralizar el bombeo de petróleo, mientras que asháninkas tomaron la ciudad de Atalaya, en Ucayali, nueve días después.

Cumplido un mes y 6 días del paro, el 15 de mayo, Alberto Pizango declaró a los pueblos amazónicos en "insurgencia" y "desconocieron" al gobierno. Sin embargo, entró rápidamente a mediar en el conflicto la Defensoría del Pueblo, la que se mantuvo en un punto medio entre el gobierno y los amazónicos a pesar de estar a favor de la derogación de los decretos. Por esta mediación, al día siguiente el mismo Pizango depuso el llamado a insurgencia, pidió diálogo al gobierno y firmó un acta de compromiso con la Defensoría del Pueblo.

El 20 de mayo se formó Comisión Multisectorial Amazónica entre AIDESEP y el Ejecutivo. Sin embargo, esto no significaba una solución al conflicto: por un lado, no se levantó el estado de emergencia en donde había sido decretado, que era el pedido de AIDESEP, "hasta que se levanten los bloqueos" según Simon; por otro lado, Pizango aclaró que la instalación de esa Comisión no significaba el levantamiento de las protestas. Más aún, dos días después de instalada esta mesa de diálogo, Pizango fue denunciado por "rebelión, sedición y conspiración" por la procuraduría debido a su llamado a la insurgencia. La dureza de las declaraciones de la Ministra de Justicia, Rosario Fernández, quien dijo que "no parará con la denuncia hasta que Pizango obtenga una sentencia condenatoria", contrastaba con la actitud dialogante mostrada por Simon apenas 48 horas antes.

El 27 de mayo, el presidente del Congreso, Javier Velásquez Quesquén (APRA), ofreció debatir la derogatoria del DL 1090 en el pleno el 4 de junio. Sin embargo, ese día la bancada aprista bloqueó el debate, al aprobar postergar la discusión, aprovechando que la mayoría de la bancada nacionalista aún no llegaba al hemiciclo. Como respuesta, AIDESEP convocó a una movilización nacional para el 11 de junio. Al día siguiente (5 de junio),

7 El paro amazónico tuvo lugar en distritos de 10 de las 25 regiones del Perú: San Martín, Amazonas, Loreto, Ucayali, Junín, Huánuco, Pasco, Madre de Dios, Cusco y Puno. 
un equipo de la policía (DINOES) intentó recuperar un sector de la carretera en Bagua tomado por los amazónicos ("la Curva del Diablo"), y la sangre llegó al río: los policías fueron con armas de fuego y los amazónicos respondieron con armas blancas. Luego de unas horas de enfrentamiento, la policía llegó a retomar la carretera, pero la indignación en los amazónicos aumentó: por un lado, prácticamente la ciudad de Bagua fue tomada por los manifestantes, quemando la comisaría y varios edificios públicos en protesta por lo que consideraban una "matanza"; por otro lado, los awajún-wampis que habían tomado la Estación $\mathrm{N}^{\circ} 6$ de Bagua al inicio del conflicto, consideraron que se había roto un pacto de no agresión con las autoridades debido al desalojo violento, y enterados también de que había amazónicos entre los muertos por el operativo, decidieron asesinar a golpes y lanzas a los rehenes que tenían con ellos. Así fueron asesinados 11 suboficiales de la policía, con claros signos de tortura. ${ }^{8}$

Si bien el gobierno responsabilizaba del hecho a Pizango y a los dirigentes de AIDESEP por su actitud "intransigente" y por "manipular" a los indígenas, lo más saltante de la información en ese día era el alto número de muertos en un solo día. Ya no sólo el Partido Nacionalista sino otras figuras públicas criticaron duramente al gobierno por la forma en que manejó el conflicto en general y por la forma de realizar el operativo en particular, la mayoría exigiendo la renuncia del gabinete Simon: al pedido de Humala se unió el de personas tan disímiles como Alejandro Toledo y el fujimorista Carlos Raffo. Por otra parte, ese mismo día Pizango pasaría a la clandestinidad para evitar así su captura.

El 8 de junio, mientras seguían saliendo a la luz detalles del operativo en Curva del Diablo (los más saltantes eran que la ejecución del operativo hecho sin la previsión necesaria y por un equipo no especializado; ausencia de la Ministra del Interior Cabanillas en su diseño; y, principalmente, la ausencia en los cálculos del Ministerio del Interior de la existencia del acuerdo con los indígenas de no agresión a los policías rehenes de la Estación $\mathrm{N}^{\mathrm{o}} 6$ cuando era previsible que, de realizar el operativo en Curva del Diablo, ellos matarían a los policías) la Ministra de la Mujer y Desarrollo Social, Carmela Vildoso, renunció por estar en desacuerdo con la forma en que el gobierno había manejado el conflicto, lo cual rompió la actitud monolítica que intentaba dar el Ejecutivo. Ese mismo día, la Embajada de Nicaragua en el Perú le concedió asilo político a Pizango.

El 10 de junio, el Congreso decidió "suspender por tiempo indefinido" los decretos legislativos, con votos a favor de la bancada aprista y de Unidad Nacional, venciendo así a la propuesta del Partido Nacionalista de derogar los decretos. Sin embargo, los dirigentes que quedaron a la cabeza de AIDESEP ante la ausencia de Pizango mantuvieron la postura de no aceptar otra cosa que no sea la derogación. Finalmente, el 14 de junio García dio su brazo a torcer. Luego de conversaciones con los dirigentes amazónicos, el ministro Simon entregó el 17 de junio al Congreso, junto con un grupo de apus de la

8 De acuerdo con el Reporte Defensoría del Pueblo al 3 de julio: un policía desaparecido y 23 muertos (12 policías murieron en una carretera en enfrentamientos con los nativos y 11 en un campo petrolero mientras eran rehenes de los nativos). 10 civiles muertos (en la carretera murieron 4 nativos; en Bagua murieron 1 nativo y 5 pobladores de la ciudad). 200 heridos y 83 detenidos. Hubo 82 heridos de bala y 9 siguen hospitalizados. Están acusadas 84 personas, de ellos 41 con orden de detención. 
Amazonia, la propuesta de derogación de los decretos legislativos demandados por los amazónicos (1090 y 1064). Ese mismo día, en un mensaje a la nación, Alan García hizo un llamado a la paz y a la reconciliación a los amazónicos, y reconoció los errores del gobierno durante el conflicto, principalmente el no consultar con las comunidades nativas los decretos legislativos. Sin embargo, hizo hincapié en que los decretos fueron hechos con "buena intención" y que fueron "distorsionados" por agitadores y violentistas. Dos días después, finalmente los decretos fueron derogados por el Congreso.

\section{Las consecuencias politicas}

El mismo día en que los decretos son derogados por el Congreso, Yehude Simon y todos sus ministros pusieron sus cargos a disposición del Presidente a raíz del conflicto amazónico. García, sin embargo, ratificó su confianza en él, y retó al Congreso a censurarlo. Desde entonces, Simon empezó a viajar por el país a solucionar los conflictos que iban estallando de manera aislada en distintas zonas. Finalmente, el 8 de julio se hizo oficial su renuncia irrevocable a través de una carta al Jefe de Estado, en la que "asume el costo político de esta desgracia que marca a toda la patria", refiriéndose a los sucesos de Bagua, que "terminaron con la vida de 34 personas". Aceptada la renuncia, fue reemplazado por Javier Velásquez Quesquén.

Por su parte, AIDESEP logró sus objetivos pero, a diferencia del paro amazónico del 2008, quedó seriamente debilitada tras dos meses de paro y con su principal dirigente asilado en Nicaragua. Después de la derogación de los decretos, se creó una mesa permanente entre AIDESEP y el Ejecutivo, la cual perdió relevancia. La estrategia del gobierno buscaría aislar a los sectores más radicales de AIDESEP.

Finalmente, existía una demanda de crear una "Comisión de la Verdad" para establecer "qué ocurrió realmente" en Bagua, pues la versión de los amazónicos era muy distinta a la manejada por el Gobierno, e incluso que la misma Defensoría del Pueblo. Esta propuesta fue recogida tanto por el Ejecutivo como por el Congreso, pero con objetivos distintos. El Gobierno creó una comisión investigadora, y ellos mismos designaron a los comisionados, entre los que se encontraban dos ex ministros del actual gobierno. Por otra parte, la Comisión del Congreso es multipartidaria y los congresistas de la oposición criticaron al APRA por querer controlar la comisión y así "entorpecer" las investigaciones; finalmente, Güido Lombardi (UN) fue elegido responsable de la comisión, en donde también participa el Partido Nacionalista. Los resultados serían públicos en el 2010.

\subsection{Las consecuencias de la herencia autoritaria en los actores institucionales}

Los regímenes presidencialistas tienden a la personalización de la toma de decisiones. Sin embargo, si las crisis políticas se resuelven agudizando el control presidencial sobre el Ejecutivo y convirtiendo el gabinete de ministros en una extensión secretarial (en el sentido peyorativo del término), se exacerban tendencias autoritarias. Este tipo de respuestas llega a ser preocupante para la consolidación democrática si se prescinde de la participación de actores que podrían contribuir al balance de poderes como el partido de gobierno. Por otro lado, el Legislativo peruano parece atrapado en la lógica 
que el fujimorismo llevó a su máxima expresión: el pragmatismo y la prebenda por sobre la cohesión ideológica y política en el comportamiento de los legisladores. A la falta de cohesión interna y al transfuguismo político (cambio de camisetas políticas en el Congreso) se le suman escándalos que día a día develan míseros actos de corrupción (i.e., abusos a sus propios empleados) de los llamados "padres de la Patria".

\section{a. El Ejecutivo: hacia una aguda concentración del poder presidencial}

Cualquier balance del segundo gobierno de Alan García incluirá definitivamente el escándalo de los Petroaudios y los sucesos de Bagua. Ambos casos, como lo sugerimos anteriormente, son emblemáticos del tipo de estructura de toma de decisiones que ha gestado la segunda administración aprista: un crecimiento económico que se ve afectado severamente por decisiones corruptas en los cabildeos de los más altos negocios en el país y una redistribución ineficaz e insensible a las demandas sociales de los grupos excluidos.

El Ejecutivo ha sentido el golpe de ambos hechos políticos. De hecho, ambos remecieron la estabilidad del gobierno, e implicaron consecuentemente cambios en el gabinete de ministros. El caso Petroaudios, aunque en su momento no afectó directamente a altos cargos políticos -más allá de operadores lobbyistas-, fue el primer golpe severo contra el Ejecutivo, al punto que el entonces Presidente del Consejo de Ministros Jorge del Castillo -y quizás la principal figura del Partido Aprista Peruano luego de García- tuvo que renunciar ante las denuncias de la prensa. Como resultado, en octubre del 2008 se dio la primera significativa reestructuración del gabinete desde la inauguración de la administración en julio del 2006. El nuevo Ejecutivo, liderado por el ex izquierdista Yehude Simon, se caracterizó por una mermada presencia aprista en los puestos ministeriales. Solo las carteras de Vivienda y Construcción y Trabajo quedaron en manos de cuadros apristas. En los restantes puestos emergieron figuras independientes, algunas de la confianza del nuevo premier (Vildoso en Mujer y Desarrollo Social, Ugarte en Salud, Leyton en Agricultura), pero permanecieron otras de demostrada fidelidad a la figura presidencial (Aráoz en Comercio Exterior y Turismo, García Belaúnde en Relaciones Exteriores, Chang en Educación) (ver cuadro en Anexo). De este modo, el gabinete Simon, con una importante presencia de independientes, surgía para capear la crisis provocada por los escándalos de corrupción que despertaban viejos e ingratos recuerdos sobre el partido aprista en el poder.

Nueve meses después, y luego de resistencias, el gabinete Simon tuvo que dar un paso al costado debido a los sucesos de Bagua. Previamente esta gestión se había renovado con la inclusión de un importante cuadro aprista en el ministerio del Interior: Mercedes Cabanillas, paradójicamente quien sería uno de los actores principales de la segunda crisis política del actual gobierno. El paro amazónico que condujo a los sucesos de Bagua evidenció las discrepancias al interior del gabinete, con una cabeza más sensible a los requerimientos sociales, pero ineficaz de ejercer su poder ante la presión de ministerios claves como Comercio (específicamente el rol de Aráoz en propugnar la permanencia de la legislación condescendiente con los tratados de comercio internacional adquiridos 
recientemente pero que afectaba directamente los intereses de las comunidades). El ministerio del Interior fue otro de los pararrayos de la crisis, debido a su ineficaz papel en la resolución de la movilización, existiendo grandes indicios de que la cadena de decisiones que ordenó la represión policial estuvo plagada de desaciertos que llevaron a los costos humanos reportados.

Cualquier Ejecutivo no podría reponerse a una crisis de la magnitud provocada por el Baguazo, sobre todo debido a la desaparición de 34 ciudadanos. Aunque se dio marcha atrás con la legislación que había provocado la movilización indígena, la pérdida de confianza entre el gobierno y la ciudadanía cayó a niveles similares a las consecuencias de los Petroaudios: sólo 20\% de la población aprobaba la gestión. Para sorpresa de los analistas que esperaban cambios sustantivos en la conformación del nuevo gabinete, García nombró a un cuadro aprista de confianza -de "segundo orden" para muchoscomo es Javier Velásquez Quesquén, quien inclusive fue percibido como un "premier fusible", acusado por sus críticos de no estar a la altura de la crítica situación. ${ }^{9}$ El nuevo gabinete trajo de vuelta al Partido Aprista al Ejecutivo, pero, a diferencia de conformaciones anteriores, evidencia la presencia ya no de líderes trajinados, sino de políticos apristas, muchos de ellos cuadros provenientes de provincias como el mismo Velásquez (Lambayeque), Vílchez (Junín), Pastor (San Martín). Asimismo se hizo más evidente la presencia de cuadros provenientes de la centroderecha (ex PPC) como Allison (Vivienda), Pérez (Comercio Exterior) y Rey (Defensa), que se suman al núcleo de confiables de García: Aráoz (que terminó el año promovida al ministerio de Economía y Finanzas), Chang (Educación) y García Belaúnde (Exterior).

La conformación del gabinete ha sido reactiva a las crisis políticas del actual gobierno. La primera (post "Petroaudios") buscó resolverse a través del ingreso de figuras independientes, muchas de ellas con lineamientos políticos de izquierda que, en teoría, le darían mayor sensibilidad a un clima social marcado por álgidas demandas sociales. Precisamente la imposibilidad de que este sector permeara el sistema de toma de decisiones detonó la segunda crisis ("Baguazo"). Esta se resolvió centralizando el poder en la figura presidencial. García renueva el gabinete con cuadros sin capital político propio más allá que la confianza presidencial, ya sean apristas de "segundo orden" promovidos al estrellato nacional (luego además de la debacle de los apristas con mayor peso envueltos en crisis políticas como Del Castillo en Petroaudios y Cabanillas en el Baguazo), fidelidades demostradas a lo largo de la actual administración (Aráoz, García Belaúnde, Chang) y la promoción de figuras opacas de la centroderecha, cuadros relativamente jóvenes y agradecidos de la venia presidencial (Allison y Pérez). El partido quedó a un lado, y García ha logrado, quizás por primera vez en este período, la mayor concentración e influencia de su poder sobre el Ejecutivo, iniciando lentamente un proceso de distanciamiento con el APRA que absorberá las mayores culpas del desprestigio del gobierno. 


\section{b. El Legislativo: la ausencia de una oposición cohesionada}

El Congreso de la República es una de las instituciones donde más claramente se puede apreciar el legado del régimen autoritario. Durante la década fujimorista el gobierno empleó estrategias informales y corruptas para obtener una mayoría parlamentaria. De hecho, el colapso del régimen se precipitó a partir de la evidencia de videos en los que el por entonces asesor del SIN Vladimiro Montesinos compraba a congresistas de la oposición para que éstos renuncien a sus bancadas de origen y se plieguen al oficialismo. Este tipo de prácticas evidenció la debilidad de las agrupaciones políticas (especialmente de los que no tenían acceso a los recursos estatales), la falta de cohesión interna, tanto a nivel disciplinario como ideológico, la ausencia de proyectos compartidos y el desencaje de sus posiciones políticas. De este modo, los grupos parlamentarios se convirtieron en simples vehículos impostores de políticos ambiciosos, sin más norte que el beneficio personal antes que la adscripción a los ideales de un proyecto político.

En un artículo anterior (Meléndez y León, 2009) señalábamos la fragilidad de las adscripciones políticas en el Legislativo peruano. La conformación de las bancadas parlamentarias varía permanentemente de un año para el otro. Unión por el Perú, agrupación de oposición elegida con el mayor número de curules (45), se fragmentó antes de iniciar la primera legislatura del nuevo gobierno, y desde entonces ha visto declinar su conformación hasta en ocho miembros (su actual conformación).

Cuadro 3: Evolución de la composición de bancadas en el Congreso de la República

\begin{tabular}{lrrrr}
\hline & \multicolumn{4}{c}{ Composición del Congreso por años } \\
\cline { 2 - 5 } & 2006 & 2007 & 2008 & 2009 \\
\hline Unión por el Perú (UPP) & 45 & 9 & 8 & 8 \\
Partido Aprista Peruano (PAP) & 36 & 36 & 36 & 36 \\
Unidad Nacional (UN) & 17 & 15 & 13 & 13 \\
Alianza para el Futuro (AF) & 13 & 13 & 13 & 13 \\
Alianza Parlamentaria (AP) & 9 & 9 & 7 & 7 \\
Partido Nacionalista Peruano (PNP) & & 22 & 23 & 22 \\
Bloque Popular (escisión UPP) & & 11 & 8 & 7 \\
Alianza Nacional (AN) & & & 6 & 8 \\
Grupo Especial Compromiso Democrático & & & & 3 \\
Sin Grupo & & 5 & 6 & 2 \\
Desaforado y en espera de reemplazo & & & & 1 \\
Total & 120 & 120 & 120 & 120 \\
\hline
\end{tabular}

Fuente: Congreso. Elaboración propia.

Sólo el partido de gobierno (PAP) y la representación parlamentaria fujimorista (AF) no han visto alterarse su conformación. Aliados en temas coyunturales, este escenario favorece a la representación oficialista en la producción legislativa a su favor. De hecho, 
la arena legislativa no es una oposición significativa para el gobierno. La inestabilidad de las filiaciones parlamentarias, sumada al desprestigio del Congreso y la falta de cohesión interna de las bancadas, hace del Congreso una arena política relativamente asequible a los intereses del gobierno. Un reciente estudio (Valladares, 2010) encuentra precisamente que los grupos con menores niveles de unidad son principalmente de oposición (es decir, UPP y PNP, los de menores coincidencias programáticas con el PAP) y que sobre todo tienen mayores dificultades para lograr acuerdos en materia económica.

De acuerdo con el Índice de Unidad que propone el autor en base al análisis de las votaciones en el pleno del Congreso durante el actual gobierno, el PAP es el grupo más unido $(0,97)$ y precisamente el opositor UPP el de menor cohesión interna $(0,70)$. Es decir, los llamados a ser oposición del gobierno no necesariamente votan en las mismas líneas que sus bancadas. La ruptura entre los opositores UPP y PNP ha mejorado los niveles de cohesión interna de ambas bancadas, precisamente sincerando a un pragmático UPP (en circunstancias votando en la misma línea que el oficialismo) y a un más consecuente opositor PNP. Sin embargo, el principal partido de oposición -PNP- no ha construido coaliciones fuertes, consideradas como superiores al 60\% de coincidencias en votos en el pleno. La única relativamente consistente ha sido con UPP, pero como indicábamos, luego de la ruptura con este grupo, el autor registra una tendencia decreciente. Si se toman las medidas de oposición y unidad de manera conjunta, el escenario resulta favorable para el oficialismo. Los grupos con mayor oposición al PAP (PNP y UPP) registran dos de los tres menores índices de unidad.

Asimismo, el Congreso es la institución pública con mayor desprestigio entre la población. De acuerdo con las encuestas de Ipsos-Apoyo (ver cuadro 1), el nivel de aprobación del Congreso ha caído a niveles ligeramente superiores al 10\%. Su ineficiencia se ve marcada sobre todo por los permanentes escándalos políticos de los congresistas. Durante el 2009, el más emblemático lo protagonizó Gustavo Espinoza (electo por UPP, pero que en el trajín se desafilió), quien fue acusado constitucionalmente debido a que envió a 50 diputados y senadores chilenos una grabación en la que se veía al ex jefe del Ejército Edwin Donayre en una reunión privada haciendo alusiones negativas a Chile, lo cual generó un nuevo impasse entre ambos países. En diciembre, el pleno del Congreso aprobó por unanimidad la acusación constitucional, y Espinoza fue inhabilitado por dos años para el ejercicio del cargo. Si sumamos diversos casos de corrupción develados por el periodismo (en especial sobre la irregularidad de contrataciones de personal por parte de los legisladores), se entiende el alto nivel de desprestigio del primer poder del Estado.

\subsection{Las consecuencias de la herencia autoritaria en los actores sociales}

Un elemento clave en la construcción del régimen autoritario durante el fujimorismo fue el control de los medios de comunicación, sobre todo a partir del empleo de estrategias mediáticas para atacar a la oposición. Los dueños de los grandes grupos comunicacionales del país, durante la década del noventa, estuvieron involucrados en los "arreglos" corruptos promovidos desde el SIN. Las evidencias muestran, por ejemplo, el nivel de 
cercanía que tuvieron José Enrique Crousillat y José Francisco Crousillat (América TV) y Genaro Delgado Parker (Pantel) en sus asiduas reuniones con Montesinos. Con la apertura del régimen político, y ante la ausencia de una oposición organizada, los medios siguen jugando un papel clave. Concentrados en un puñado de grupos económicos, tienen quizás más capacidad de influencia que muchos partidos. En una democracia sin partidos, los medios asumen los roles de fiscalización y definición de la agenda, sin los reparos y atingencias propias de los actores que rinden cuentas a sus electorados.

Así como la ausencia de partidos implica que sean actores privatizados como los medios los que terminen cumpliendo roles de definición de la agenda política y fiscalización a la actual administración, a nivel de las esferas locales y regionales su significativa ausencia influye en el alto nivel de conflictividad social. Los canales de intermediación política están ausentes y las demandas son movilizadas por operadores políticos independientes, sin filiaciones ni compromisos, que pueden llevar al radicalismo de las protestas. El sistema político peruano no se recompone de la ausencia de partidos, es hasta ahora incapaz de restablecerlos como actores que influyan positivamente en la política mediática y en la política de base.

\section{a. La oposición mediática}

La década de 1990 demostró el papel de los medios de comunicación en la manipulación de ciertas tendencias en la opinión pública peruana. El régimen autoritario fujimorista se basó, entre uno de sus elementos más importantes, en una gran influencia sobre la agenda informativa de la prensa tanto televisiva como escrita (Fowks, 2001). En un contexto de ausencia de partidos políticos y de una oposición orgánica tanto con presencia en el Legislativo como con influencia entre la ciudadanía, el rol de los medios de comunicación es amplificado ante la debilidad de la oposición política. De hecho, son periodistas independientes los que terminan fijando la atención del gobierno como principales contendores a sus intereses políticos. La salida de Augusto Álvarez Rodrich de la dirección de Perú21 (uno de los principales diarios de circulación nacional) puede interpretarse dentro de este contexto ${ }^{10}$.

En este escenario, es relevante fijar la atención sobre la concentración de la propiedad de los medios de comunicación en el Perú actual. De hecho, los principales medios de comunicación del país (tanto escritos, televisivos y radiales) se encuentran en manos de cuatro grupos de poder: el Grupo El Comercio, de la familia Miró Quesada; el grupo La República, de la familia Mohme; el grupo Epensa (Diario Correo), de la familia Agois Banchero; y RPP, de Manuel Delgado Parker, los mismos que concentran más del 90\% del mercado. El restante porcentaje es distribuido por la Cadena Peruana de Noticias (de los hermanos Baertl), por el diario La Primera (de Martin de Belaúnde, asesor de Ollanta Humala durante la campaña presidencial del 2006) y por la tradicional revista política Caretas, de propiedad de la familia Zileri.

10 Diario Correo controla el 25,7\% del mercado de prensa escrita, mientras que tres diarios del Grupo El Comercio (El Comercio, Trome y Perú21) controlan el 37\% (Becerra y Mastrini, 2008). 
Cuadro 4: Concentración de los medios de comunicación

\begin{tabular}{|c|c|c|}
\hline Grupo económico & Medios del Grupo & Propiedad de \\
\hline El Comercio & $\begin{array}{l}\text { El Comercio, Depor, Gestión, Trome, Perú21, } \\
\text { Canal N, América TV }\end{array}$ & Familia Miró Quesada \\
\hline La República & $\begin{array}{l}\text { La República, Libero, El Popular; América TV y } \\
\text { Canal N en minoría. }\end{array}$ & Familia Mohme \\
\hline Epensa & Correo, Ojo, Ajá, El Bocón & Familia Agois Banchero \\
\hline RPP & $\begin{array}{l}\text { RPP, Radio Capital, Studio 92, Oxígeno F.M., } \\
\text { Radio Felicidad y La Mega. }\end{array}$ & Manuel Delgado Parker \\
\hline
\end{tabular}

Fuente: Revista Poder y propia.

\section{b. La oposición conflictiva}

El caso de Bagua (que vimos anteriormente) ejemplifica el tipo de oposición social que enfrenta el gobierno y los desafíos que tiene el régimen democrático en su conjunto (Grompone y Tanaka, 2009). Desde que la Defensoría del Pueblo lleva el registro de conflictos sociales, éstos han mantenido una tendencia creciente que se ha radicalizado en los últimos dos años, llegando a su máximo en octubre del 2009 con casi 300 conflictos sociales activados en todo el país (ver Gráfico 3). Precisamente el crecimiento económico parece contradecirse con la creciente insatisfacción social movilizada que ha llegado a niveles inéditos hacia el final de la primera década del siglo XXI.

Estos conflictos, sin embargo, cuando llegan a escalar a nivel nacional (como las repercusiones del "Baguazo") lo hacen de manera coyuntural. La característica principal del tipo de conflictividad social que atraviesa el país es precisamente el nivel de desarticulación que existe entre conflictos de similares características. Los actores que promueven la movilización de las demandas sociales son débiles y, en la mayoría de los casos, de alcance local. No se trata de organizaciones sociales tradicionales (partidos políticos, sindicatos, gremios, etc.), sino generalmente de asociaciones civiles efímeras ("frentes de defensa") cuya organicidad depende de una demanda específica que se radicaliza, pero incapaz de agregar sus requerimientos con grupos similares, inclusive en zonas vecinas. Si vemos la clasificación de conflictos sociales por tipo de demanda (Gráfico 4) podemos apreciar que casi la mitad de ellos abordan el tema socioambiental, pero no existe organización social nacional que pueda arrogarse la representación (ni siquiera la movilización) de este tipo de demanda. Los sindicatos de trabajadores agrupados en la Central Unica de Trabajadores del Perú (CGTP) -otrora gremio tradicional- quedan limitados al 10\% de las demandas movilizadas.

Esta limitación perjudica tanto a los movilizados como al Estado. En el primer caso, la solución a los requerimientos también es coyuntural y por lo tanto precaria, incentivando una lógica del gobierno de "apaga incendios" antes que un tratamiento más integral a la problemática. Por el lado del gobierno, la diversidad de actores impide enfocar las estrategias de tratamiento de los conflictos, lo que sumado a la subvaloración de los actores involucrados no crea los incentivos para una solución definitiva a las demandas. 
Gráfico 3: Total de conflictos sociales

(Marzo 2004-diciembre 2009)

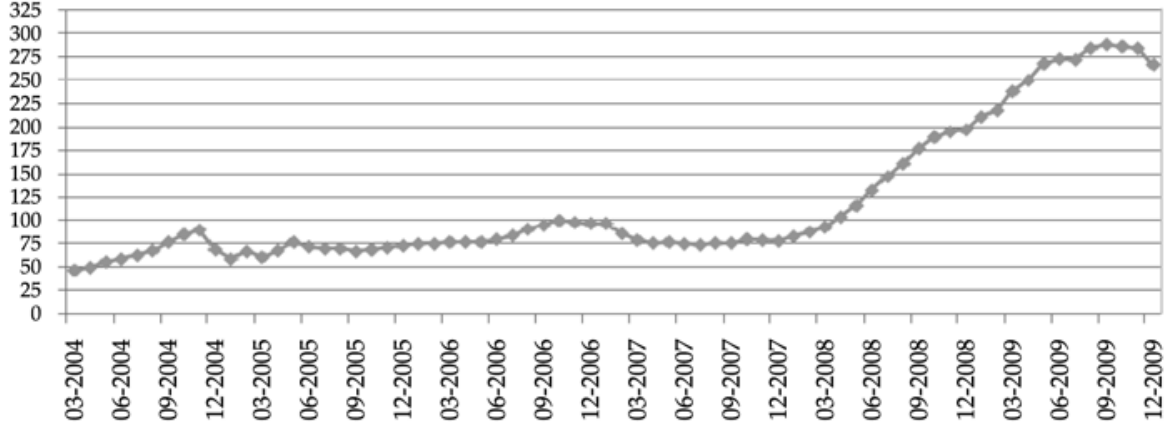

Fuente: Defensoría del Pueblo.

Gráfico 4: Conflictos sociales según tipo

(Total 2009)

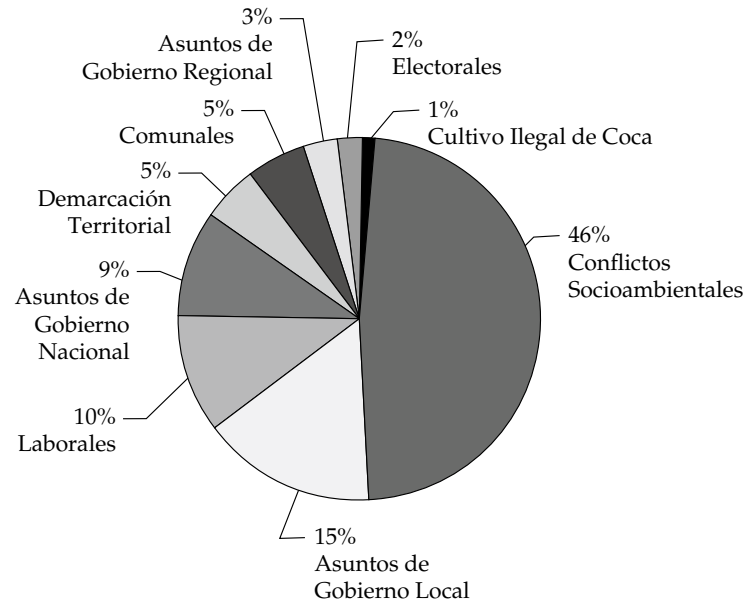

Fuente: Defensoría del Pueblo.

De hecho, la estrategia del gobierno ante el paro amazónico (caso Bagua) ejemplifica la estrategia de "zanahoria y garrote" que ha venido aplicando frente a la conflictividad social: por un lado, llamando a reuniones con el Ministro Simon (independiente y con fama de conciliador y dialogante) en Lima para tratar el tema y buscar salidas conjuntas; por otro, se establecían toques de queda y se declaraban estados de emergencia en distritos en donde la protesta de AIDESEP era más fuerte. Casi similar a una estrategia del desgaste. Sin embargo, este procedimiento hace que la tensión crezca y no disminuya el alcance de la protesta. Se apela a la debilidad del actor social, y sólo escala en conflicto nacional en los pocos casos en que los actores que protestan cuentan con los recursos para ello (como el caso de AIDESEP). 
Las negociaciones del gobierno tienen una misma dinámica: no ceder en la demanda central (no derogación, en el caso de Bagua), ofrecer otro tipo de soluciones ("correcciones a la ley") y continuar con el diálogo. En cambio, el objetivo de los movilizados (como AIDESEP) es más preciso: derogatoria de los decretos legislativos para levantar el paro, aun si esto podía costar vidas ("moriremos defendiendo nuestro territorio", dijo Alberto Pizango). Por ello, las propuestas de diálogo aprobadas por parte del gobierno son calificadas como "mecidas" (promesas que no se cumplirán) pues no tocan la solución definitiva de los requerimientos sociales.

\section{CONCLUSIONES: UNA DEMOCRACIA CON LEGADOS AUTORITARIOS}

Las interpretaciones más convencionales sobre el sistema político peruano en el siglo XXI lo han caracterizado como una "democracia sin partidos" (Tanaka, 2005) y como el producto de una "escisión inevitable" entre la clase política y la sociedad (Grompone, 2005). Se ha enfatizado en las reformas participativas que han venido de la mano de la apertura democrática (Remy, 2004) y las tensiones sociales que se generan en una economía en crecimiento pero sin la capacidad de una redistribución eficiente de los recursos (Grompone y Tanaka, 2009). Sin embargo, no se ha hecho el énfasis necesario en la permanencia de estrategias, lógicas de comportamiento y legados del régimen autoritario que colapsó con la renuncia de Fujimori en el 2000.

Los escándalos políticos que han afectado la estabilidad del gobierno en el período de análisis se originan precisamente en la activación de dos legados autoritarios: la permanencia de una red de espionaje telefónico debido a la demanda de este tipo de tácticas de parte de los actores que toman decisiones (incluyendo a personajes cercanos al gobierno) y la represión de la movilización social en un contexto de ausencia de intermediación política. Tanto el caso de los Petroaudios y el Baguazo son la evidencia de la consecuencia negativa de un proceso de desmontaje del autoritarismo dejado a medias, y de la superficialidad de las reformas emprendidas para mejorar los niveles de competencia política. Queda claro que ellas no han sido suficientes.

Sin embargo, y a pesar de las crisis políticas que ha generado la activación de los legados autoritarios, el gobierno de García aún mantiene el equilibrio de gobernabilidad a partir del juego paralelo en dos "tableros": el institucional y el social (Meléndez y León, 2009). El gobierno ve afectados su imagen y prestigio, pero las crisis no ponen en jaque la estabilidad del gobierno ni la legitimidad del régimen democrático. La desafección con respecto a los gobernantes y a la política aumenta, pero ante la ausencia de una oposición con vínculos con los conflictos sociales o cohesionados internamente en el Parlamento, la administración García sobrelleva los temporales a pesar de la gravedad de los sucesos de Bagua y de los escándalos de corrupción de los Petroaudios. 


\section{REFERENCIAS}

Becerra, Martín y Guillermo Mastrini (2008). Los dueños de la palabra. Acceso, estructura y concentración de medios en la América Latina del Siglo XXI. Buenos Aires: Prometeo.

Cotler, Julio y Romeo Grompone (2000). El fujimorismo. Lima: Instituto de Estudios Peruanos.

Degregori, Carlos Iván (2000). La década de la antipolítica. Lima: Instituto de Estudios Peruanos.

Degregori, Carlos Iván y Carlos Meléndez (2007). El Nacimiento de los Otorongos. Lima: IEP.

Fowks, Jacqueline (2000). Suma y resta de la realidad. Los medios de comunicación y las elecciones generales 2000 en el Perú. Lima: Fundación Friedrich Ebert.

Gorriti, Gustavo (2010). Petro Audios. Lima: Planeta.

Grompone, Romeo (2005). La escisión inevitable. Partidos y movimientos en el Perú actual. Lima: IEP.

Grompone, Romeo y Martin Tanaka (eds.). (2009). Entre el crecimiento económico y la insatisfacción social Lima: Instituto de Estudios Peruanos.

Meléndez, Carlos y Carlos León (2009). “Perú 2008: El juego de ajedrez de la gobernabilidad en partidas simultáneas". En: Revista de Ciencia Política, volumen 29, número 2, pp. 591-609.

Tanaka, Martin (2005). Democracia sin partidos. Lima: Instituto de Estudios Peruanos.

Tanaka, Martin y Sofía Vera (2010). "La dinámica neodualista de una democracia sin sistema de partidos: La situación de la democracia en el Perú". En: Revista de Ciencia Política, volumen 30, número 1, pp. 87-114.

Valladares, Jorge (2010). “Unidad de los grupos parlamentarios en el Congreso de la República 20062007". En: Valladares, Jorge (coordinador), Estudios sobre el Congreso Peruano. Grupos parlamentarios, disciplina partidaria y desempeño profesional. Lima: IDEA Internacional e Instituto Ética y Desarrollo de la Universidad Ruiz de Montoya.

Carlos Meléndez, estudiante del Programa de Doctorado de Ciencia Política de la Universidad de Notre Dame (Indiana, Estados Unidos).

[E-mail: cmelend1@nd.edu]

Carlos León, Bachiller de Ciencia Política por la Pontificia Universidad Católica del Perú.

[E-mail: carlos.leon@pucp.edu.pe] 


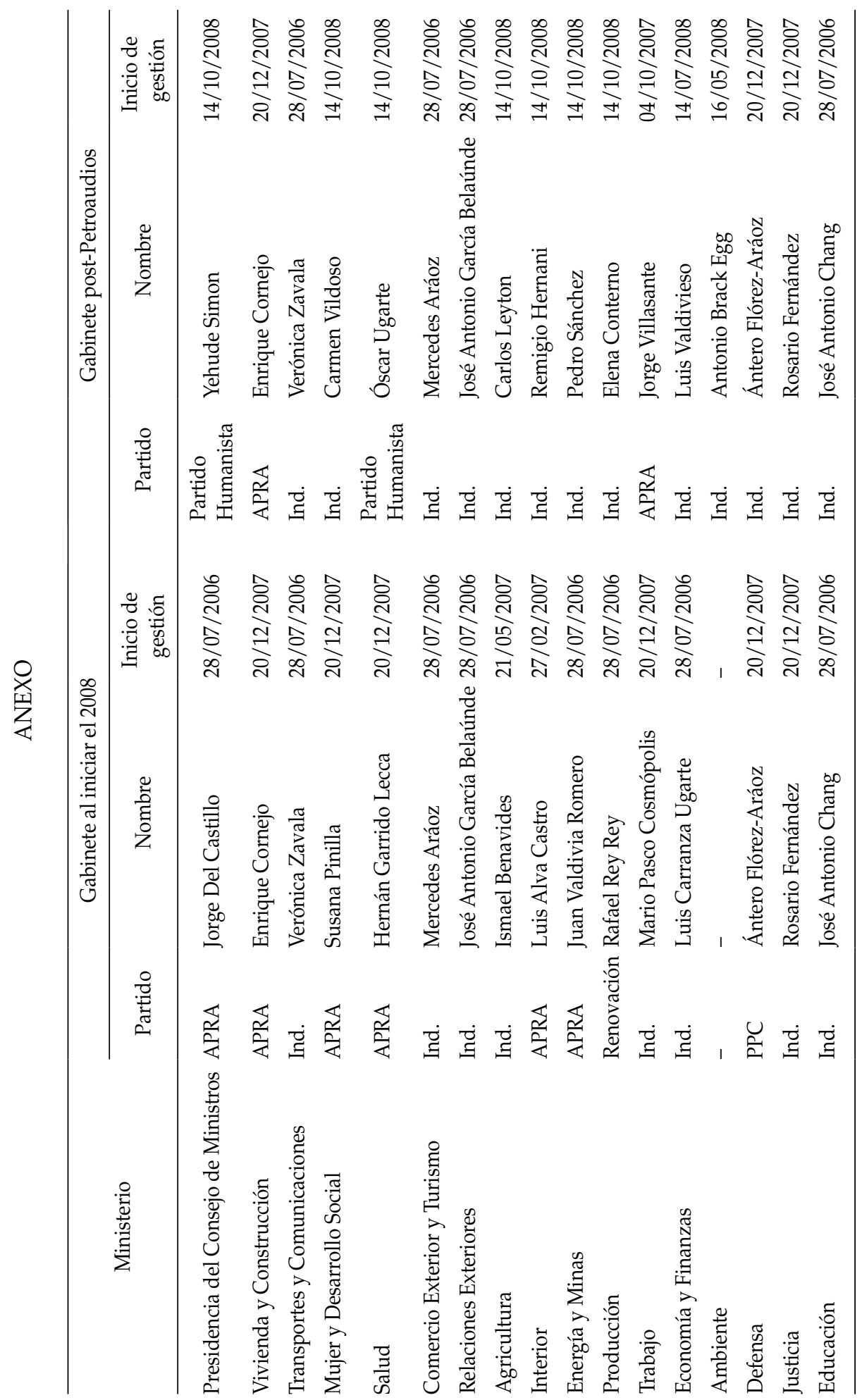




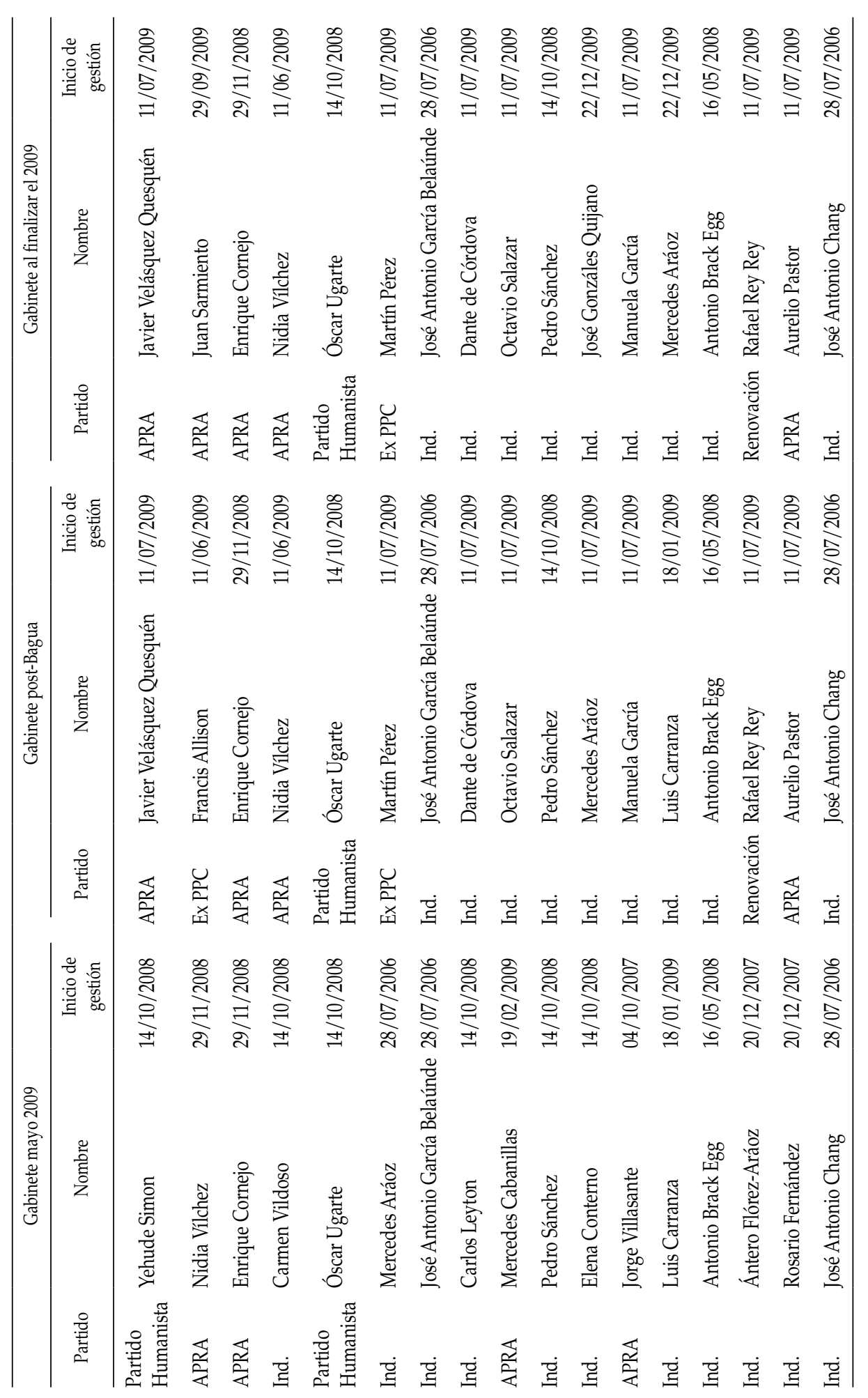


